\title{
Lung Cancer; Approaches for Immunotherapy and Immune Chemotherapy
}

\author{
Nasim Rahmani Kukia ${ }^{1}$, Ardeshir Abbasi ${ }^{2 *}$ and Zuhair Mohammad Hassan ${ }^{2}$ \\ ${ }^{1}$ Department of Microbiology, Urmia University, Iran \\ ${ }^{2}$ Department of Immunology, Tarbiat Modares University of Medical Sciences, Iran
}

Submission: March 20, 2018; Published: March 28, 2018

*Corresponding author: Ardeshir Abbasi, Department of Immunology, Tarbiat Modares University of Medical Sciences, Tehran, Iran: Tel: 989187262126, Email: ardeshir.abbasi66@gmail.com

\begin{abstract}
Lung cancers are one of the most frequent cancer and causing death for both men and women in the world. Through the acceptance of novel biomarkers, it has been possible to recognize subsets of patients who reap the benefits of targeted molecular solutions. The success of targeted anticancer remedies and new immunotherapy methods has created a fresh paradigm of personal therapy and has also led to accelerated development of new drugs for lung cancer treatment. In addition to, recently Monoclonal antibodies to programmed death 1 and its ligand are now approved for both first and second brand treatment patients with metastatic lung cancers. In this Summary, we will put together the explanation and current research strategies looking into the role of immunotherapy and immune chemotherapy in resectable non-small cell lung cancers (NSCLC), as well as potential new targets for drug development.
\end{abstract}

Keywords: Non-small cell lung cancers; Biomarker; Immunotherapy; Immune chemotherapy

\section{Introduction}

Like all malignancies, Cancers of the lung, results from an abnormal proliferation cells in the body. Normally, our body maintains a system of mounts and inspections on cell progress so that skin cells divide to produce new cells only when new organ cells are needed. Disruption of this system of assessments and balances on cell development results within an uncontrolled division and proliferation of cells that eventually forms a mass known as a hyperplasia and may will progress to neoplasia [1]. Three main types of lung cancer; knowing which kind we have important since it affects our treatment options and your perspective (prognosis). These include small cell lung cancers (SCLC), non-small cell lung malignancies (NSCLC) and lung carcinoid tumor.

About $85 \%$ of lung cancers are NSCLCs, $10 \%-15 \%$ SCLC and less than $5 \%$ lung carcinoid tumor. The level of lung malignancy refers to the level of spread in the body. In addition, lung cancer cell can spread to other organ in the body, certain locations particularly the adrenal glands, liver, brain, and bones are the most frequent sites for lung malignancy metastasis [2]. Also the lung is a very common site for metastasis from malignant tumors in other parts of the body. Reports from the North American Cancer Society predicted that in 2018 we will see about 244,000 new cases of lung cancer tumor in the U.S.A [4] and over 154,000 fatalities of disease. Lung cancer tumor is predominantly an illness of older people; almost $70 \%$ of people diagnosed with lung tumor are over 65 years, while it is less than $3 \%$ of lung malignancies occur in people under 45 years. The median get older at identification is 70 years [5]. Treatment of lung tumor can require a combination of surgery, chemotherapy, targeted remedy, immunotherapy, radiation therapy.

Different malignancies have different risk factors. Some risk factors, like smoking, can be altered the cell to hyperplasia. Others, like an individual's age or family background, cannot be changed [6]. But having a risk factor does not mean that you will get the disease. And a lot of people who get the disease may have few or any known risk factors. Some risk factor can be changed include: Cigarettes smoke, exposure to the product, Arsenic in drinking normal water and certain health supplements. And some risk factor are unable to changed include; air pollution, Personal or family history and ancestors of lung cancer and factors with unsure or unproven effects on lung cancer risk such Smoking marijuana and Talcum powder [7].

\section{Lung Cancer Biomarkers}

Biomarkers are simply just defined as components we can use to distinguish abnormal from normal status .In the recent years, the molecular abnormalities in a sizable proportion of patients 
has allowed the emergence of individualized targeted remedies and has opened new horizons and created new expectations for these patients [6]. The use of predictive biomarkers to identify tumors that may respond to targeted treatments has meant an alteration in the paradigm of lung cancers diagnosis [7]. It has been possible to identify subsets of patients who reap the benefits of targeted molecular therapies. The success of targeted anticancer solutions and new immunotherapy approaches has created a new paradigm of personalized therapy and has also Table1: Lung Cancer Biomarkers. led to accelerated development of new drugs for lung cancer tumor treatment. Table 1 includes cancers biomarkers as targets for therapy. Malignancy biomarkers can consist of most biomolecules used for medical purposes, including protein, genetic materials such as DNAs, methylated DNAs, RNAs, and microRNAs (miRNAs), oligosaccharides, lipids, and metabolites, because tumor is a heterogeneous disease that display gene and health proteins changes in a cancer cell $[8,9]$.

\begin{tabular}{|c|c|c|}
\hline Genomic Biomarkers & Type of Lung Cancer and Specificity & References \\
\hline EGFR & NSCLC 62\% $\%]$ & {$[11]$} \\
\hline ALK & NSCLC 7\% & {$[12]$} \\
\hline KRAS & NSCLC 35\% & {$[13]$} \\
\hline HER2 & NSCLC 34\% & {$[14]$} \\
\hline Protein Biomarkers & & {$[15]$} \\
\hline CYFRA21-1 & NSCLC 89\% & {$[16]$} \\
\hline CEA & NSCLC 90\% & {$[17]$} \\
\hline NSE & SCLC 98\% & {$[18]$} \\
\hline ProGRP & SCLC 95\% & {$[19]$} \\
\hline Micro RNA Biomarkers & & {$[19]$} \\
\hline miRNA-34 & NSCLC 80\% & \\
\hline miR-21, miR-126 & NSCLC 96\% & \\
\hline miR-210 & NSCLC 96\% & \\
\hline
\end{tabular}

Abbreviations: EGFR: Epidermal Growth Factor Receptor; ALK: Anaplastic Lymphoma Kinase; KRAS: Kirsten Rat Sarcoma Viral Oncogene Homolog; HER2: Human Epidermal Growth Factor Receptor 2; CEA: Carcinoembryonic Antigen; CYFRA21-1: Cytokeratin 19 Fragment, NSE: Neuron-Specific Enolase; ProGRP: Progastrin-Releasing Peptide

\section{Immunotherapies for Lung Cancer}

\section{Nonspecific immunotherapy for lung cancer}

The efforts of nonspecific immune system stimulationbased therapies have yielded equivocal results. The properties of lung tumors to evade immunosurveillance is a result of the creation of immunosuppressive chemokines of the tumor cells, loss of MHC antigen manifestation, and higher amounts of T-regulatory (Treg) the tumor microenvironment $[20,21]$. However Restorative vaccines have been used to top rated the host disease fighting capability to recognize tumor antigens and augment antitumor T-cell reactions; two types of vaccines are being examined in NSCLC: tumor cell and antigen-based vaccines [22]. Immunization against tumor epitopes (alternative splicing peptides) is attained by injections of recombinant tumor antigen proteins, peptides, or gangliosides that subsequently activate humoral and mobile immune replies against tumor antigens [23]. Immunotherapy uses both dynamic and passive replies of the immune system to treat various kinds of malignancy. Although immunotherapeutic brokers have been approved for quite some time now to treat such cancers as melanoma and lymphoma, NSCLC was at one time considered nonimmunogenic or not susceptible to immune- mediated killing of cancer cells, mostly because of failed attempts at immunomodulation with interleukin-2, interferon, and Bacillus Calmette-Guerin. However, clinical advances have led to the creation of immunotherapies that ease the suppression of antitumor activity in a number of cancers, including situations of advanced NSCLC [24]. Productive immunotherapy modulates the disease fighting capability and has been classified as nonspecific and specific, the previous of which is seen as a general immune system response and the latter of which consists of the stimulation of humoral and cellmediated immunity. Examples of active immunotherapeutic real estate agents include recombinant cytokines, bio chemotherapy, cancer vaccines, and immunomodulatory monoclonal antibodies [25]. On the other hand Immune checkpoints make reference to inhibitory pathways vital for retaining self-tolerance; tumors use certain checkpoint pathways to escape immune surveillance [26]. Inhibitory ligands and receptors that regulate T-cell effectors functions are generally overexpressed in tumor skin cells or in the tumor microenvironment. Then, the blockade of immune checkpoints releases the breaks on the immune system leading to antigen-specific T-cell replies.

\section{Specific Immunotherapy for lung cancer}

Chemotherapy to surgery as adjuvant or neoadjuvant treatment can improve success rates by about $5 \%$ at 5 years. Lately, major developments in cancer tumor immunotherapy have resulted in better outcomes for most patients with lung cancers. Immunotherapy has used immune system cells or 
monoclonal antibodies for stimulated immune system [27]. Monoclonal antibodies to programmed death 1 and its ligand are now approved for both first and second range treatment patients with metastatic lung malignancy. Lately, treatment with immunotherapy ligands (programmed cell death-1)PD_1, PD-L1 and (T-lymphocyte-associated antigen-4)CTAL-4 can improve final results compare to chemotherapy for NSCLC patient in the metastatic setting has leading lots of clinical trials.in addition to, immunotherapy has less toxicity than compared to cytotoxic chemotherapy [28]. Peruse analysis showed that immunotherapy evolved immunosuppressive microenvironment in lung tumors [29]. Furthermore, the Researchers has shown PD1/PDL1 inhibitor remedy for advanced NSCLC has a significantly higher objective response rate (ORR) and a higher rate of immune system-mediated pneumonitis when used in front-line setting when compared with chemotherapy cared for patients. Various anti-PD-1/PD-L1antibodies are already approved for the firstand second-line setting up. There are a number of monoclonal antibody for inhibits PD1 like: Nivolumab and pembrolizumab and for PDL1 inhibit atezolizumab that Food and Medicine Supervision (FDA) approved treatments for patients with NSCLC [30]. However ipilimumab, is available to prevent the binding of CTLA-4 with its ligands (CD80/CD86), resulting in reactivation of the antitumor immune response mediated by specific $\mathrm{T}$ cells [31].

Peruse study validated the NSCLCs exhibit and exposed PDL1 for inhibit function effect or T skin cells in microenvironment tumor. Then, T adapted treatment of cancer tumor cells not very successful. In this regard, scientific studied and looked into for outcome this problem. Nonetheless, PD-L1 manifestation has been associated with EGRF mutation, which has been reported to correlate with a higher likelihood of respond to PD-1 blockade, recommending that immunotherapy in EGFR-mutant NSCLC may still maintain promise. Osimertinib is an oral, third-generation, irreversible epidermal growth factor receptor tyrosine kinase inhibitor (EGFR-TKI) that selectively inhibits both EGFR-TKIsensitizing [32]. Osimertinib proved efficacy more advanced than that of standard EGFR-TKIs in the first-line treatment of EGFR mutation-positive advanced NSCLC, with an identical safety profile and lower rates of serious negative events. Then, recently immunotherapy has success options for treating cancer therapy.

\section{Proposed Immune chemotherapy for lung cancer}

Current work are concentrating on new potential combination strategies with synergistic antitumor activity, using immune checkpoint blockade as a partner for targeted real estate agents and toxin conjugate anti PDL1 and lead toxin to internalize inside tumor cell [33]. Tumor cell death brought on by chemotherapeutic and targeted agencies strengthens the antitumor immune response by release of neoantigens. This offers a unique opportunity for combo strategies with synergistic antitumor activity, using immunotherapy as a partner for chemotherapy, targeted brokers and other immune system checkpoint inhibitors [34]. Herein we discuss the available data on the blended use of immunotherapy, including PD-1/PD-L1 and CTLA- 4 inhibitors, with EGFR and ALK inhibitors and touch upon the current status of immunotherapy plus antiangiogenic drugs for molecularly unselected advanced NSCLC. Antiangiogenic providers focusing on the vascular endothelial progress factor (VEGF) and VEGF receptor (VEGFR) have also reshaped the approach to the treatment of advanced NSCLC. For instance: A period review of ipilimumab in combination with chemotherapy in patients with advanced NSCLC revealed very promising results, with a significant improvement in PFS versus a control group cured with chemotherapy only [34]. On the other hand, among the important portion of the immune system, cytokines play an integral role in tumor suppression, which induce functional immune cell proliferation and the secretion of inflammatory cytokines to eliminate cancer cells [35]. Cytokine treatments have been applied extensively in various solid tumor and lymphadenoma due to their favorable curative effect [36]. Recently, many studies have been conducted on the blend of cytokines and chemotherapy, that could cause activation of the innate disease fighting capability and inhibit the tumor expansion more proficiently $[37,38]$.This combined immune-chemo treatment against cancer may start a new way for improved cytokine remedy in cancers treatment. For instance: investigate the anti-cancer effects and mechanisms of immunochemotherapy of 5-fluorouracil (5-FU) and interleukin-2 (IL-2) on non-small cell lung cancer tumor (NSCLC) A549 cells. Combination remedy significantly inhibited tumor growth in comparison with monotherapy with 5-FU or IL-2 and enhanced the identification and lysis of tumor cells by NK skin cells. 5-FU and IL-2 immunochemotherapy significantly inhibited tumor development and turned on NK cytotoxicity in vivo. Therefore, all of the data suggested that combo immunotherapy and chemotherapy may provide a new treatment option for patients with lung tumors [39].

\section{Conclusion}

Immunotherapy with monoclonal antibodies to PD-1 and PDL1 are now approved for treatment of patients with metastatic NSCLC, and also have been shown in several randomized tests to lead to raised outcomes for select patients in comparison to standard chemotherapy. Studies are currently underway evaluating the safest and most effective ways of combine these treatments in the multi-disciplinary management of patients with resectable NSCLC. Studies with additional immunotherapy realtors, including combo immunotherapies, chemoimmunotherapy, and CAR-T cells, will build on our current understanding and add ideally yield new treatments that lead to better final results for patients with early-stage NSCLC.

\section{References}

1. Shotton R, D Patterson (2018) Audit of systemic therapies for older patients with lung cancer in a DGH setting. Lung Cancer 115(1): S55. 
2. Jamal HM, Wilson GA, Nicholas M, Nicolai JB, Thomas BKW, et al. (2017) Tracking the evolution of non-small-cell lung cancer. New England Journal of Medicine 376(22): 2109-2121.

3. Siegel RL, KD Miller, A Jemal (2018) Cancer Statistics, 2018. CA: A Cancer Journal for Clinicians 68(1): 7-30.

4. Baglietto L, Ponzi E, Haycock P, Hodge A, Bianca Assumma M, et al. (2017) DNA methylation changes measured in pre-diagnostic peripheral blood samples are associated with smoking and lung cancer risk. Int J Cancer 140(1): 50-61.

5. Islami F, Goding Sauer A, Miller KD, Siegel RL, Fedewa SA, et al. (2018) Proportion and number of cancer cases and deaths attributable to potentially modifiable risk factors in the United States. CA Cancer J Clin 68(1): 31-54

6. Smith RA, Andrews KS, Brooks D, Fedewa SA, Manassaram BD, et al. (2017) Cancer screening in the United States, 2017: a review of current American Cancer Society guidelines and current issues in cancer screening. CA Cancer J Clin 67(2): 100-121.

7. Villalobos P, II Wistuba (2017) Lung cancer biomarkers. Hematol Oncol Clin North Am 31(1): 13-29.

8. Chen ST (2016) Lung cancer biomarker. Google Patents.

9. Del VV, Grasso M, Barbareschi M, Denti MA, et al. (2014) MicroRNAs as lung cancer biomarkers. World J Clin Oncol 5(4): 604.

10. Sharma SV, Bell DW, Settleman J, Haber DA, et al. (2007) Epidermal growth factor receptor mutations in lung cancer. Nature Reviews Cancer 7(3): 169-181.

11. Sholl LM (2014) Biomarkers in lung adenocarcinoma: a decade of progress. Arch Pathol Lab Med 139(4): 469-480.

12. Kempf E, Rousseau B, Besse B, Paz Ares L (2016) KRAS oncogene in lung cancer: focus on molecularly driven clinical trials. Eur Respir Rev 25(139): 71-76.

13. Xu Y, Xu L, Qiu M, Wang J, Zhou Q et al. (2015) Prognostic value of serum cytokeratin 19 fragments (Cyfra 21-1) in patients with nonsmall cell lung cancer. Sci Rep 5: 9444.

14. Wang XB, J Li, Y Han (2014) Prognostic significance of preoperative serum carcinoembryonic antigen in non-small cell lung cancer: a metaanalysis. Tumor Biology 35(10): 10105-10110.

15. Wang B, He YJ, Tian YX, Yang RN, Zhu YR, et al. (2014) Clinical utility of haptoglobin in combination with CEA, NSE and CYFRA21-1 for diagnosis of lung cancer. Asian Pac J Cancer Prev 15(22): 9611-9614.

16. Kim HR, Oh IJ, Shin MG, Park JS, Choi HJ, et al. (2011) Plasma proGRP concentration is sensitive and specific for discriminating small cell lung cancer from nonmalignant conditions or non-small cell lung cancer. J Korean Med Sci 26(5): 625-630.

17. Bianchi F, Nicassio F, Marzi M, Belloni E, Dallolio V, et al. (2011) A serum circulating miRNA diagnostic test to identify asymptomatic high-risk individuals with early stage lung cancer. EMBO Mol Med 3(8): 495-503.

18. Shen J, Todd NW, Zhang H, Yu L, Lingxiao X, et al. (2011) Plasma microRNAs as potential biomarkers for non-small-cell lung cancer Laboratory investigation 91(4): 579.

19. Dasanu CA, Sethi N, Ahmed N (2012) Immune alterations and emerging immunotherapeutic approaches in lung cancer. Expert Opin Biol Ther 12(7): 923-937.

20. Woo EY, Yeh H, Chu CS, Schlienger K, Carroll RG, et al. (2002) Cutting edge: regulatory $\mathrm{T}$ cells from lung cancer patients directly inhibit autologous $\mathrm{T}$ cell proliferation. The Journal of Immunology 168(9): 4272-4276

21. Anagnostou VK, JR Brahmer (2015) Cancer immunotherapy: a future paradigm shift in the treatment of non-small cell lung cancer. Clin
Cancer Res 21(5): 976-984.

22. Carter BW, Halpenny DF, Ginsberg MS, Papadimitrakopoulou VA de Groot PM (2017) Immunotherapy in Non-Small Cell Lung Cancer Treatment: Current Status and the Role of Imaging. Journal of thoracic imaging 32(5): 300-312.

23. Bhatia S, SS Tykodi, JA Thompson (2009) Treatment of metastatic melanoma: an overview. Oncology (Williston Park) 23(6): 488

24. Guo C, Masoud HM, John RS, Devanand S, Paul B, Xiang YW, et al. (2013) Therapeutic cancer vaccines: past, present, and future, in Advances in cancer research. Elsevier pp. 421-475.

25. Galluzzi, L, Vacchelli E, Bravo San Pedro JM, Buqué A, Senovilla L, Baracco EE, et al. (2014) Classification of current anticancer immunotherapies. Oncotarget 5(24): 12472-12508.

26. Anagnostou V, Smith KN, Forde PM, Niknafs N, Bhattacharya R, et al. (2017) Evolution of neoantigen landscape during immune checkpoint blockade in non-small cell lung cancer. Cancer discovery 7(3): 264276.

27. Hirsch FR, McElhinny A, Stanforth D, Ranger Moore J, Jansson M, et al. (2017) PD-L1 immunohistochemistry assays for lung cancer: results from phase 1 of the blueprint PD-L1 IHC assay comparison project. J Thorac Oncol 12(2): 208-222.

28. Owen D, JE Chaft (2018) Immunotherapy in surgically resectable nonsmall cell lung cancer. Journal of Thoracic Disease 10(3): S404-S411.

29. Khunger M, Jain P, Rakshit S, Pasupuleti V, Hernandez AV, et al. (2018) Safety and efficacy of PD-1/PD-L1 inhibitors in treatment naïve and chemotherapy refractory patients with Non-small cell lung cancer: a systematic review and meta-analysis. Clin Lung Cancer.

30. Seetharamu N, DR Budman, KM Sullivan (2016) Immune checkpoint inhibitors in lung cancer: past, present and future. Future Oncol 12(9): 1151-1163.

31. Soria JC, Yuichiro O, Johan V, Thanyanan R, Busyamas C, et al. (2018) Osimertinib in untreated EGFR-mutated advanced non-small-cell lung cancer. New England Journal of Medicine 378(2): 113-125.

32. Moya Horno I, Santiago Viteri, Niki Karachaliou, Rafael Rosell (2018) Combination of immunotherapy with targeted therapies in advanced non-small cell lung cancer (NSCLC). Therapeutic Advances in Medical Oncology 10: 1758834017745012.

33. Lynch TJ, Bondarenko I, Luft A, Serwatowski P, Barlesi F, et al. (2012) Ipilimumab in combination with paclitaxel and carboplatin as firstline treatment in stage IIIB/IV non-small-cell lung cancer: results from a randomized, double-blind, multicenter phase II study. Journal of Clinical Oncology 30(17): 2046-2054.

34. Wang CY, MW Mayo, AS Baldwin, (1996) TNF-and cancer therapy-

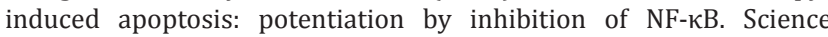
274(5288): 784-787.

35. Wu X, Yundi Wua, Hong boYe, Shuangjiang Yu, Chaoliang He et al. (2017) Interleukin-15 and cisplatin co-encapsulated thermosensitive polypeptide hydrogels for combined immuno-chemotherapy. Journal of Controlled Release 255: 81-93.

36. He C, Zhaohui Tang, Huayu Tian, Xuesi Chen (2016) Co-delivery of chemotherapeutics and proteins for synergistic therapy. Advanced Drug Delivery Reviews 98: 64-76.

37. Ribas A, F. Stephen Hodi, Cyril Konto, Jedd Wolchok, et al. (2013) Hepatotoxicity with combination of vemurafenib and ipilimumab. New England Journal of Medicine 368(14):1365-1366.

38. Zhao L, Wang WJ, Zhang JN, Zhang XY (2014) 5-Fluorouracil and interleukin-2 immunochemotherapy enhances immunogenicity of non-small cell lung cancer A549 cells through upregulation of NKG2D ligands. Asian Pac J Cancer Prev 15(9): 4039-4044. 


\section{Your next submission with Juniper Publishers} will reach you the below assets

- Quality Editorial service

- Swift Peer Review

- Reprints availability

- E-prints Service

- Manuscript Podcast for convenient understanding

- Global attainment for your research

- Manuscript accessibility in different formats

(Pdf, E-pub, Full Text, Audio)

- Unceasing customer service

Track the below URL for one-step submission https://juniperpublishers.com/online-submission.php 